\title{
Introducing mole fraction in the density calculations of liquid-liquid solutions
}

\author{
Mutasim I. KhaliI ${ }^{1 *}$, Reem A. H. Al-Yami ${ }^{2}$ and Manal H. Al-Khabbas ${ }^{2}$ \\ ${ }^{1}$ Department of Chemistry, Faculty of Science, King Saud University, P. O. Box 2455, Riyadh 11451, Saudi Arabia. \\ ${ }^{2}$ Department of Chemistry, Girls College, Hail University, Hail, Saudi Arabi.
}

Accepted 15 December, 2012

\begin{abstract}
The densities of an ideal and a non-ideal liquid-liquid solution were determined experimentally. The experimental results were then compared to calculated values using two mathematical expressions for density, employing partial densities in one and mole fraction in the other. Results were presented in form of tables and graphs, indicating the validity of applying mole fractions in the estimation of liquidliquid solutions.
\end{abstract}

Key words: Density, ideal solution, non-ideal solution, mole fraction.

\section{INTRODUCTION}

Density is a variable of state for a thermodynamic system meaning that, it depends on its values at the initial and final pressure and temperature state (Lago and Gluliano, 2011). The mass density or density, $\rho$, of a material is defined as its mass per unit volume, or, also, weight per unit volume. It is an intensive property indicating how tight the particles are packed inside the substance and it can be expressed as:

$\rho=m / V$

Where,

$\rho=$ Density $\left(\mathrm{kg} / \mathrm{m}^{3}\right.$ or $\left.\mathrm{g} / \mathrm{cm}^{3}\right)$

$\mathrm{m}=$ Mass $(\mathrm{kg}$ or $\mathrm{g})$

$\mathrm{V}=$ Volume $\left(\mathrm{m}^{3}\right.$ or $\left.\mathrm{cm}^{3}\right)$

The most used units for density are the SI units $\left(\mathrm{kg} / \mathrm{m}^{3}\right)$ and the cgs units $\left(\mathrm{g} / \mathrm{cm}^{3}\right)$, and it is a dimensionless quantity when expressed as specific gravity (SG) or relative density (RD). Densities of materials differ and it is an important concept regarding buoyancy, purity, and packaging. It could be used to identify the material or calculate its volume mass and can also be used in analyzing how materials interact in fluid mechanics,

*Corresponding author. E-mail: mkhalil@ksu.edu.sa. Tel: 0096614675973. Fax: 0096614675992. weather, geology, material sciences, engineering, and other fields of Physics.

Density concept is also thought of, as a spatial concept that is used as a tool in predicting and controlling land use (Boyko and Cooper, 2011). It is used as a metric by decision makers from many different disciplines and professions (Churchman, 1999). In that sense, it may be defined as a number of units in a given area, for example, number of people per hectare or number of dwellings in $\mathrm{km}^{2}$ (Boyko and Cooper, 2011).

Experimental determination of density occupies a central place for several reasons. In one hand, measurements of density as a function of pressure and temperature allow to obtain two derived properties, the isobaric thermal expansivity and the isothermal compressibility (Rowlinson and Swinton, 1982). An experimental methodology for precise determination of density of room temperature ionic liquids as a function of temperature and pressure using vibrating tube densimeter was proposed by Sammamed et al. (2010). In fact, recently, there has been an increasing interest in the thermodynamics of room temperature ionic liquids (Marsh et al., 2004; Heintz, 2005), which are classified as potential "green" substitutes for the volatile organic compounds commonly used in industry (Holbrey and Seddon, 1999).

The determination of liquids density is usually carried out by weighing the mass of a measured volume of liquid using a digital balance. Most of the workers deal with experimental measurements of thermophysical 
Table 1. Density values of liquids used.

\begin{tabular}{lc}
\hline Material & Density $\mathbf{~} / \mathbf{c m}^{\mathbf{3}}$ \\
\hline Water & 1.0 \\
$96 \%$ ethanol & 0.79 \\
Benzene & 0.88 \\
Carbon tetrachloride & 1.59 \\
\hline
\end{tabular}

Table 2. Experimental and calculated density data for ethanol - water solutions.

\begin{tabular}{|c|c|c|c|c|c|c|c|}
\hline \multirow{2}{*}{ Exp. no. } & \multicolumn{2}{|c|}{ Volume (\%) } & \multicolumn{2}{|c|}{$\rho$ partial (calc.) } & \multirow{2}{*}{$\rho_{\text {T exp. }}$} & \multicolumn{2}{|c|}{$\rho_{\text {calc. }}$} \\
\hline & $\mathrm{H}_{2} \mathrm{O}$ & $\mathrm{C}_{2} \mathrm{H}_{5} \mathrm{OH}$ & $\mathrm{H}_{2} \mathrm{O}$ & $\mathrm{C}_{2} \mathrm{H}_{5} \mathrm{OH}$ & & $\Sigma \rho_{i} V_{i} / V_{t}$ & $\sum x_{i} \rho_{i}$ \\
\hline 1 & 100 & 0.00 & 1.0 & 0.00 & 0.988 & 1.0 & 1.0 \\
\hline 2 & 83.3 & 16.70 & 0.833 & 0.131 & 0.959 & 0.965 & 0.988 \\
\hline 3 & 62.5 & 37.50 & 0.615 & 0.296 & 0.916 & 0.921 & 0.968 \\
\hline 4 & 50.0 & 50.00 & 0.50 & 0.395 & 0.892 & 0.895 & 0.95 \\
\hline 5 & 41.66 & 58.34 & 0.416 & 0.460 & 0.873 & 0.877 & 0.936 \\
\hline 6 & 35.7 & 64.30 & 0.357 & 0.507 & 0.860 & 0.865 & 0.924 \\
\hline 7 & 31.25 & 68.75 & 0.312 & 0.543 & 0.853 & 0.855 & 0.914 \\
\hline
\end{tabular}

properties at atmospheric pressure. Since the effect of pressure and temperature on the densities of liquids is small, determinations of liquids density are done at ambient temperature and pressure.

On the other hand, the density of a solution is the sum of mass concentrations of the components of that solution. Mass concentration of a given component $\rho i$ in a solution can be called partial density of that component:

$\mathrm{P}=\Sigma \rho \mathrm{i}$

Expressed as a function of the densities of pure components of the mixture and their volume participation, it reads:

$\rho=\Sigma \rho i V_{i} / V_{t}$

\section{EXPERIMENTAL}

\section{Materials and apparatus}

Distilled water, 96\% ethanol (PANREAC QUIMICA SA), benzene (PANREAC QUIMICA SA), and carbon tetrachloride (E.MERK D6100, Darmstadi, F.R. Germany) are used.

\section{Instruments and apparatus}

A four decimal digital balance, four burettes, two $25 \mathrm{ml}$ beakers, and glass wares commonly found in laboratories were used

\section{Instructions}

The non-ideal solutions were prepared from distilled water and $96 \%$ ethanol. $5.0 \mathrm{ml}$ of water was added from burette and its weight was recorded. From another burette containing $96 \%$ ethanol, different portions of known volumes were added and the weights were recorded after each addition. The weight of $5.0 \mathrm{ml}$ of ethanol was determined separately. While, the ideal solutions were prepared from benzene and carbon tetrachloride and the weights were determined similarly. A minimum of six readings were taken. The experimental density values were then compared to the calculated ones using the mathematical expressions in Equations 3 and 4:

$\rho=\Sigma X_{i} \rho_{i}$

Where,

$\rho_{i}$ is the literature density values (Table 1), (Furniss et al., 1989), $V_{i}$ and $V_{t}$ are the component and total volumes, respectively, and $x_{i}$ is the mole fraction of component.

\section{RESULTS AND DISCUSSION}

The results were presented in Tables 2 to 4 and Figures 1 to 4 . Tables 2 and 3 lists the volume percent of solutions components, the partial density of each component in the different solutions, the experimental total densities of solutions and the calculated densities using Equations 3 and 4 . The data are presented graphically by Figures 1 , 2 , and 3 . Table 4 lists the mole fractions, partial densities of components and the total densities of the as prepared different ideal solutions. The data are graphically presented in Figure 4.

It is evident that Equation 4 is valid for non-ideal solutions, while both Equations 3 and 4 could be used to estimate the densities of ideal solutions. It was observed that there is a close analogy between the behavior of density and vapour pressure variations of ideal and nonideal solutions. 
Table 3. Experimental and calculated density data for benzene - carbon tetrachloride solutions.

\begin{tabular}{|c|c|c|c|c|c|c|c|}
\hline \multirow{2}{*}{ Exp. no. } & \multicolumn{2}{|c|}{ Volume (\%) } & \multicolumn{2}{|c|}{$\rho$ partial (calc.) } & \multirow{2}{*}{$\rho_{\mathrm{texp}}$} & \multicolumn{2}{|c|}{$\rho_{\text {calc. }}$} \\
\hline & $\mathrm{C}_{6} \mathrm{H}_{6}$ & $\mathrm{CCl}_{4}$ & $\mathrm{C}_{6} \mathrm{H}_{6}$ & $\mathrm{CCl}_{4}$ & & $\Sigma \rho_{i} V_{i} / V_{t}$ & $\Sigma x_{i} \rho_{i}$ \\
\hline 1 & 100 & 0.0 & 0.878 & 0.00 & 0.891 & 0.877 & 0.878 \\
\hline 2 & 00.0 & 100 & 0.00 & 1.59 & 1.587 & 1.59 & 1.59 \\
\hline 3 & 83.3 & 16.7 & 0.731 & 0.265 & 0.993 & 0.995 & 0.988 \\
\hline 4 & 62.5 & 37.5 & 0.548 & 0.596 & 1.143 & 1.144 & 1.134 \\
\hline 5 & 50.0 & 50.0 & 0.439 & 0.795 & 1.233 & 1.233 & 1.233 \\
\hline 6 & 41.66 & 58.34 & 0.365 & 0.927 & 1.294 & 1.292 & 1.279 \\
\hline 7 & 33.33 & 66.67 & 0.292 & 1.06 & 1.354 & 1.352 & 1.339 \\
\hline 8 & 29.41 & 70.59 & 0.258 & 1.122 & 1.381 & 1.380 & 1.368 \\
\hline 9 & 25.00 & 75.0 & 0.219 & 1.192 & 1.413 & 1.411 & 1.401 \\
\hline 10 & 20.00 & 80.0 & 0.175 & 1.272 & 1.449 & 1.447 & 1.438 \\
\hline 11 & 16.66 & 83.34 & 0.146 & 1.325 & 1.472 & 1.471 & 1.463 \\
\hline
\end{tabular}

Table 4. Mole fractions and partial densities of $\mathrm{C}_{6} \mathrm{H}_{6}$ and $\mathrm{CCl}_{4}$ and total densities.

\begin{tabular}{|c|c|c|c|c|c|}
\hline \multirow{2}{*}{ Exp. no. } & \multicolumn{2}{|c|}{$\mathrm{C}_{6} \mathrm{H}_{6}$} & \multicolumn{2}{|c|}{$\mathrm{CCl}_{4}$} & \multirow{2}{*}{$\rho_{\text {T }}$} \\
\hline & $x$ & $\rho$ & $x$ & $\rho$ & \\
\hline 1 & 0 & 0 & 1 & 1.59 & 1.59 \\
\hline 2 & 1 & 0.878 & 0 & 0 & 0.878 \\
\hline 3 & 0.845 & 0.742 & 0.155 & 0.246 & 0.988 \\
\hline 4 & 0.646 & 0.567 & 0.356 & 0.567 & 1.134 \\
\hline 5 & 0.521 & 0.458 & 0.479 & 0.775 & 1.233 \\
\hline 6 & 0.437 & 0.384 & 0.563 & 0.895 & 1.279 \\
\hline 7 & 0.352 & 0.309 & 0.648 & 1.03 & 1.339 \\
\hline 8 & 0.312 & 0.274 & 0.688 & 1.094 & 1.368 \\
\hline 9 & 0.266 & 0.234 & 0.734 & 1.167 & 1.401 \\
\hline 10 & 0.214 & 0.188 & 0.786 & 1.25 & 1.438 \\
\hline 11 & 0.179 & 0.157 & 0.821 & 1.306 & 1.463 \\
\hline
\end{tabular}

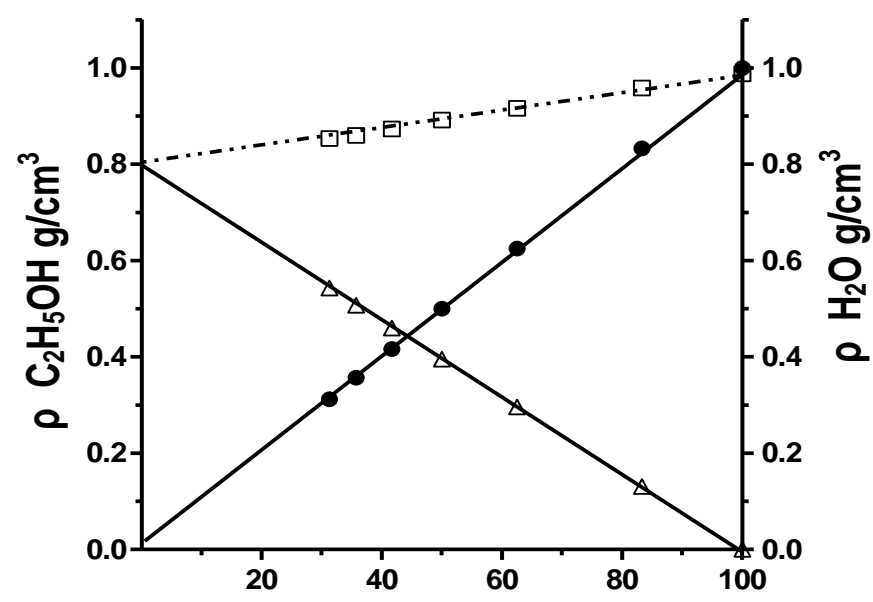

$\mathrm{H}_{2} \mathrm{O}$ volume (\%)

Figure 1. $\mathrm{H}_{2} \mathrm{O}$ volume (\%) versus partial and total densities of water-ethanol solutions ( $\square \rho_{\mathrm{T}}$ exp.; $\Delta \rho_{\mathrm{T}}$ partial density of ethanol; $\bullet$ $\rho_{\text {T }}$ partial density of $\mathrm{H}_{2} \mathrm{O}$ ). 


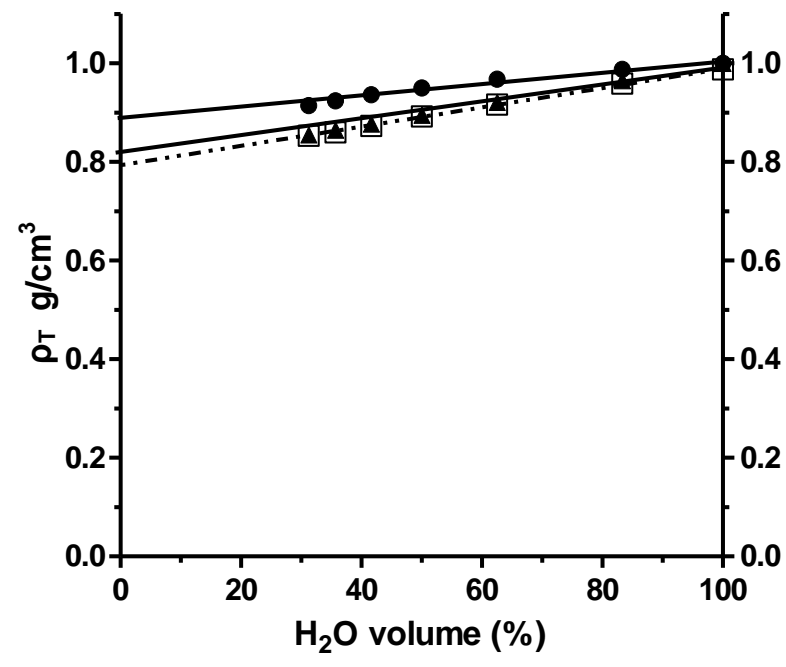

Figure 2. $\mathrm{H}_{2} \mathrm{O}$ volume (\%) versus total densities ( $\left.\rho_{T}\right)$ of

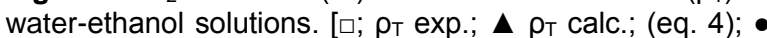
$\rho_{\text {T }}$ calc. Equation 5].

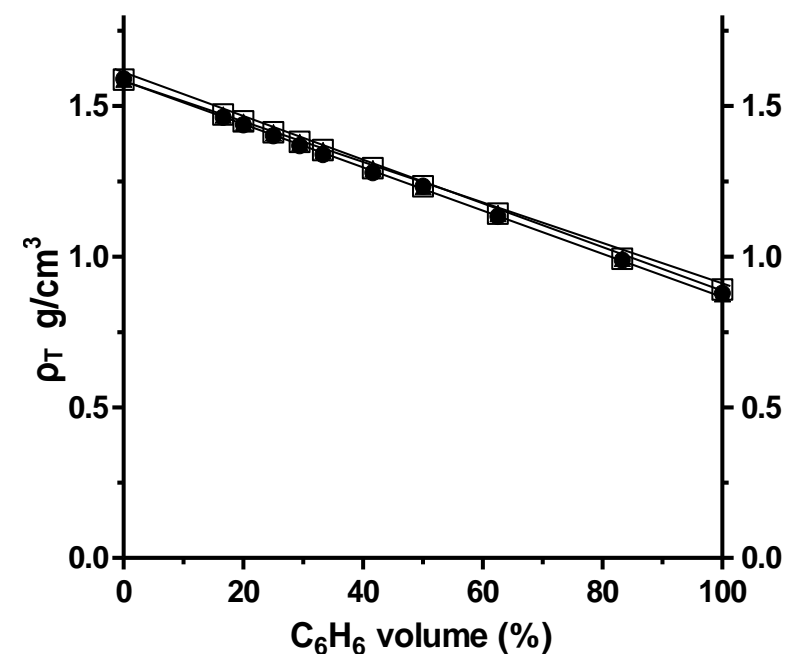

Figure 3. $\mathrm{C}_{6} \mathrm{H}_{6}$ volume (\%) versus total density $\left(\rho_{\mathrm{T}}\right)$. $\square \rho_{\mathrm{T}}$ exp.; $\Delta \rho_{\mathrm{T}}$ calc. (eq. 4); $\bullet \rho_{\mathrm{T}}$ calc. (eq. 5).

\section{Conclusion}

In conclusion, one could estimate the density of liquid liquid solutions employing the mole fraction of solution component. The results obtained are in good agreement with the experimental values. This will help much students and research workers where a densometer or even a digital balance is unavailable.

\section{ACKNOWLEDGEMENTS}

This project was supported by King Saud University, Deanship of Scientific Research, College of Science Research Center.

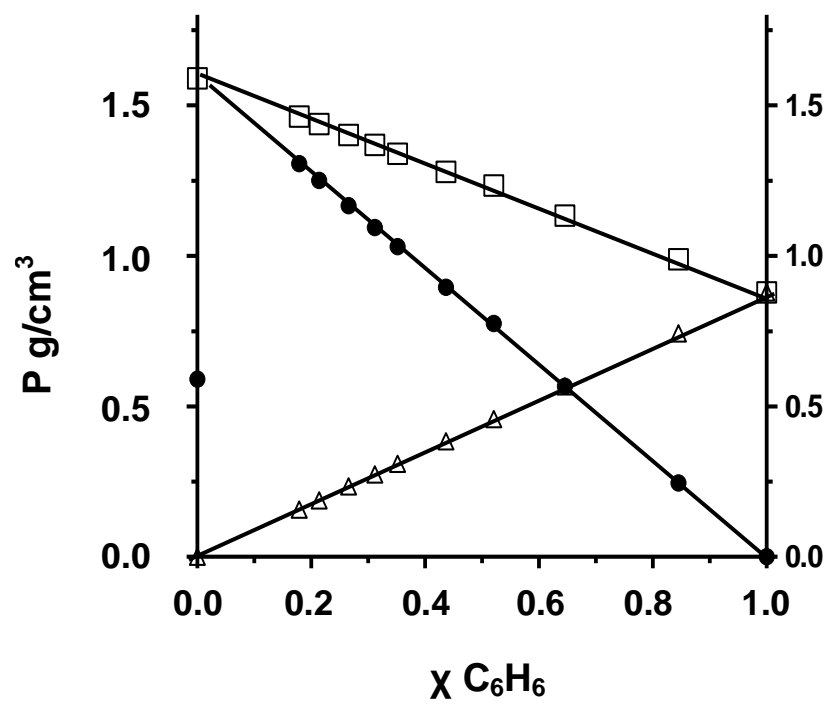

Figure 4. $\mathrm{C}_{6} \mathrm{H}_{6}$ mole fraction, $X$, versus. total $\left(\square \rho_{T}\right)$ and partial densities of $\mathrm{C}_{6} \mathrm{H}_{6}(\bullet)$ and $\mathrm{CCl}_{4}(\Delta)$.

\section{REFERENCES}

Boyko CT, Cooper R (2011). Clarifying and re-conceptualising density. Prog. Plann. 76:1-61.

Churchman R (1999). Sisintagling the concept of density. J. Plann. Lit. 13(4):389-411.

Furniss BS, Hannaford AJ, Smith PWJ, Tatchell AR (1989). Vogle's Textbook of Practical Organic Chemistry,5th ed.; Longman Scientific and Technical. London. pp. 1442-1445.

Heintz AJ (2005). Recent devolopment in thermodynamic and thermophysics of non-aqueous mixtures containing ionic liquids. Chem. Thermodyn. 37(6):525-535.

Holbrey JD, Seddon KR (1999). Ionic Liquids. Clean Prod. Process. 1:223-236.

Lago S, Gluliano APA (2011). A recursive equation method for the determination of density and heat capacity: Comparison between isentropic and isothermal integration path. J. Chem. Thermodyn. 42(4):462-465.

Marsh KN, Boxal JA, Lichtenthaler R (2004). Room temperature ionic liquids and their mixtures. Fluid Phase Equilib. 219(10):93-98.

Rowlinson JS, Swinton FL (1982). Liquid and Liquid Solutions (third ed.) Butterworth and Co. London.

Sammamed YA, Gonzalez-Salgado D, Troncosoa J, Romania L, Baylaucq A, Boned C (2010). Experimental methodology for precise determination of density. J. Chem. Thermodyn. 42(4):553-563. 